\title{
VIZAG GAS LEAK- A CASE STUDY ON THE UNCONTROLLED STYRENE VAPOUR RELEASE FOR THE FIRST TIME IN INDIA
}

\author{
Dr Yashoda Tammineni ${ }^{1}$ \\ Head of the Department,National Institute of Fire Engineering and Safety Management \\ Visakhapatnam \\ Teja Dakuri $^{2}$ \\ M.Tech, Pursuing Industrial Safety, National Institute of Fire Engineering and Safety \\ Management, Visakhapatnam
}

Article DOI: https://doi.org/10.36713/epra4907

\begin{abstract}
Industrial emergencies involving hazardous chemicals are not uncommon in India. During the last several decades there has been a growing awareness of the expanding risks and consequences of major industrial disasters. Industrial hazards can occur at any stage in the production process, including extraction, processing, manufacture, transportation, storage, use, and disposal. Losses generally involve the release of damaging substances (e.g. chemicals, radioacvity) or damaging levels of energy from industrial facilities or equipment into surrounding environments. This usually occurs in the form of explosions, fires, spills, leaks, or wastes. In a recent occurrence on the wee hours of 7 th May 2020, an accident of uncontrolled release of Styrene vapor occurred at LG Polymers India Pvt. Ltd. (LG Polymers) in RR Venkatapuram Village, Visakhapatnam from one of the Styrene storage tanks. The hazardous Styrene vapors spread beyond the factory premises, affecting the populace of five villages / habitations. The officials from the District administration along with Police Department, GVMC, National Disaster Response Force (NDRF) and local people rushed to the spot for rescue operations. However, the grave accident led to 12 citizens losing their lives and 585 citizens being hospitalized. In this regard let's take a brief look into the causes of the accident which led to this grave mishap.
\end{abstract}

KEYWORDS: Vizag gas leak, styrene vapour, MSIHC 1989, Pre-Startup Safety Review (PSSR), Hazardous Material Information System (HMIS), Process safety management.

\section{INTRODUCTION}

On 7th May 2020, an incident of uncontrolled Styrene vapour Release occurred at LG Polymers, RR Venkatapuram, Visakhapatnam from one of the Styrene storage-tanks (M6 Tank). The uncontrolled Styrene vapour release from a storage tank into the atmosphere occurred for the first time in India.

The accident took the life of 12 persons in the immediate subsequent period and 585 people had to undergo treatment in hospitals, besides causing loss of livestock and vegetation. This Styrene vapour release, 


\section{EPRA International Journal of Research and Development (IJRD) \\ Volume: 5 | Issue: 8 | August 2020 \\ - Peer Reviewed Journal}

widely referred to as "Vizag Gas Leak", is one of the major Styrene vapour release incidents from a bulk storage tank anywhere in the world. It was decided that a team from CBRN (Chemical, Biological, Radiological and Nuclear) unit of NDRF from Pune, along with an expert team of National Environmental Engineering Research Institute (NEERI), Nagpur would be rushed to Vishakhapatnam immediately to support the State Government in the management of the crisis on the ground.

The National Disaster Management Authority arranged a special aircraft for airlifting joint team of four response experts from 5th Battalion, NDRF Pune along with PPE, other equipment and five environmental experts from Nagpur. The aircraft reached Visakhapatnam on 7th May and the team immediately supported the local administration in controlling the situation.

As per the Manufacture, Storage and Import of Hazardous Chemicals Rules, (MSIHC) 1989,-' "major accident" means an occurrence including any particular major emission, fire or explosion involving one or more hazardous chemicals and resulting from uncontrolled developments in the course of an industrial activity or due to natural events leading to serious effects both immediate or delayed, inside or outside the installation likely to cause substantial loss of life and property including adverse effects on the environments."

As per the above definition, the uncontrolled Styrene vapour release from the M6 Tank at LG Polymers Visakhapatnam, commonly reported as "Vizag Gas Leak" qualifies as a major accident under MSIHC Rules, 1989.

\subsection{About LG Polymers, Visakhapatnam}

Industrial activity at the current premises of M/s LG Polymers at R.R. Venkatapuram, Visakhapatnam started in 1961, under the name and style of M/s Sri Rama Mills to manufacture alcohol from molasses. Later, in $1962 \mathrm{M} / \mathrm{s}$ Sri Rama Mills was taken over by M/s Hindustan Polymers Ltd. In 1967 (as per Factories Department License), M/s Hindustan Polymers Ltd. replaced the manufacturing activity of alcohol with manufacturing activity of Polystyrene \& Co-Polymer. Manufacturing of Styrene Monomer was reportedly initiated in 1973. In 1978, M/s Hindustan Polymers Ltd. merged with McDowell \& Co. Ltd of United Breweries Group. The Company terminated manufacturing of Styrene monomer and started importing it in the year 1993 .

As per the information provided by the management, the LG Chemicals (South Korea) Ltd set up the LG Chemicals India Pvt. Ltd., as a $100 \%$ subsidiary of LG Chemical, South Korea. The LG Chemicals India Pvt. Ltd. acquired M/s Hindustan Polymers Ltd in 1997 and renamed the company as M/s LG Polymers India Private Limited, Visakhapatnam. The LG Polymers is a $100 \%$ subsidiary of LG Chemicals India Pvt. Ltd. After acquisition, the LG Polymers continued manufacturing of Polystyrene \& Expandable Polystyrene and expanded the manufacturing capacities from time to time.

At present, LG Polymers is spread over a total area of 213 Acres and engaged in manufacturing of Polystyrene used for General Purpose Polystyrene (GPPS) \& High Impact Polystyrene (HIPS) to the tune of 313 Tons per day, Expandable Polystyrene (EPS) to the tune of 102 Tons per day and Engineering Plastics 36.67 Tons per day. M/s LG Polymers is storing Styrene, Pentane and other raw materials within the plant premises.

\section{REASONS FOR THE RELEASE OF STYRENE VAPOUR IN LG POLYMERS INDIA PVT. LTD.}

The first term of reference is to enquire into the reasons for leakage including verifying if the company had adhered to all the safety protocols. The studies reveal that there are number of contributory factors which led to the accident as per the observations received from the various inputs by the committee. During the deliberations, the following quote of Trevor A. Kletz was noted by the committee "A case history shows that an accident generally does not have one cause, but many, and that, the deeper we go, the more causes we find."

Major Raw Materials:

a) Styrene Monomer

b) Ethyl Benzene

c) Pentane

\subsection{Styrene Monomer storage M6 Tank} involved in the accident

This tank was originally constructed by Hindustan Polymers Ltd. It was initially used for storing Molasses from 1967. Later it was converted as Styrene storage tank. The PESO authorities at Visakhapatnam confirmed that the plan of this tank was approved and the license for filling this tank were accorded by PESO under Petroleum Act \& Rules in 1977.

\subsection{Activities during the lockdown}

a) It is reported that before the Covid-19 lockdown was imposed, the manufacturing activities were carried out normally. Owing to the lockdown, the factory was shut 


\section{EPRA International Journal of Research and Development (IJRD)}

Volume: 5 | Issue: 8 | August 2020

- Peer Reviewed Journal

down on the intervening night of 24th / 25th March 2020.

b) For the maintenance of the plant during the lockdown period, LG Polymers had applied permission for 60 persons, of which they received permission to engage 45 persons (at the rate of 15 per shift) by the district administration.

c) All the factories except those in containment zones were relaxed from the Covid-19 lockdown with effect from 4th May 2020 and allowed to resume operations. The management had proposed to undertake the restart of the factory from 7th May 2020. LG Polymers stated that as per the Covid-19 protocol, they carried out activities like cleaning, sanitization, disinfestations etc. between 4th to 6th May 2020.

d) Regular day to day activities were undertaken on 6th May 2020 at LG Polymers. The refrigeration of Styrene storage tanks M5 \& M6 was stopped around 03.45 p.m. All the other activities in Styrene Monomer Handling (SMH) area were also closed by 05:00 p.m., with chiller

\subsection{Reasons for uncontrolled release of Styrene vapour in LG Polymers}

The temperature recorded in the M6 Tank from 05:00 p.m. of 6th May 2020 to 09:00 a.m. of 9th May 2020 , by the DCS. It is evident from the temperature graph that the temperature probe was by and large stable below $20^{\circ} \mathrm{C}$ until about 03:00 a.m. of 7th May 2020 and started increasing thereafter. The rise in temperature was sudden and occurred at a fast rate. The rate of increase of temperature slightly reduced between 05:00 a.m. to 09:00 a.m. and thereafter again started increasing. From 03:00 p.m. there was a further increase in the rate and finally the temperature peak of $153.7^{\circ} \mathrm{C}$ was recorded at about 10:00 p.m. The Technical Committee has estimated that the boiling temperature of Styrene monomer is $153.7^{\circ} \mathrm{C}$ at 1.25 atm. This also indicates that the pressure of $1.25 \mathrm{~atm}$ developed in the M6 Tank due to limited sized vents, which led to uncontrolled Styrene vapour release. There is a flat line between the time 10:00 p.m. of 7th May 2020 to about 3:00 a.m. of 8th May 2020, implying that the temperature remained constant. The temperature in the tank started reducing from 03:00 a.m. of 8th May 2020 and the temperature reduced to $58.8^{\circ} \mathrm{C}$ at 7:00 a.m. on 16th May 2020.

It is also important to note that M6 Tank was insulated. This implies that the heat generated in the M6 Tank was by and large not transmitted outside. The insulation was reported to be partially stripped as a part of the emergency response measures to enable faster cooling of the M6 Tank after the accident.

\section{ANALYSIS OF PREVIOUS STYRENE RELATED ACCIDENTS}

The determination of the root cause of the Styrene vapour release needs knowledge and analysis of previous accidents. From the records compiled on similar accidents and literature available, it is understood that accidents occurring due to runaway reactions are limited and in most of those accidents, runaway reaction had resulted in explosion of the tank. The LG Polymers Styrene vapour release from a bulk storage tank is a unique and exclusive accident. The only accident, called as Cincinnati Styrene Release, on 28th August 2005, from a rail tanker containing about 80 MT of Styrene, has been reported before. It was stated in the report - "The safety valve had opened to release excessive pressure build up, slowly avoiding a catastrophic explosion". The error was that the stationary rail car was allowed for nine months, during which time the inhibitor became depleted and possibly the temperature increased due to ambient heat. The increase in pressure was attributed to heat generated within the tank due to polymerisation of the Styrene monomer within the tank.

The Technical Committee has followed the Guidelines for Investigating Process Safety Incidents issued by the "Centre for Chemical Process Safety, American Institute of Chemical Engineers (AIChE)" for the root cause analysis.

\subsection{Parameters that contributed to the calamitous accident}

All the factors/parameters have been analyzed to arrive at the root cause of uncontrolled Styrene vapour release from the M6 Tank of LG Polymers. The parameters that influenced the increase of temperature of Styrene in the tank (M6) are categorized into the following:

1) Tank Design,

2) Tank Temperature Measurement and Control,

3) Recirculation and Refrigeration System,

4) Inhibitor Addition Protocols,

5) Polymerisation \& Runaway reaction.

\section{TANK DESIGN}

The M6 Tank is made of mild steel without any inside lining and insulated outside. It operates under atmospheric pressure and has a Flame Arrestor / Vent (N6) and a Vent / Dip hatch (N1). In addition, there is a manhole / foam pourer (N2). There are a total of 17 nozzles in the M6 Tank. 


\section{EPRA International Journal of Research and Development (IJRD)}

Volume: 5 | Issue: 8 | August 2020

\begin{tabular}{|l|l|}
\hline Tank Size & Dia: 18.002 Mtrs. Height: $12.15 \mathrm{Mtrs}$. \\
\hline Total Capacity - KL & 3090.96 \\
\hline Operating Capacity - KL/MT & $2450 / 2200$ \\
\hline
\end{tabular}

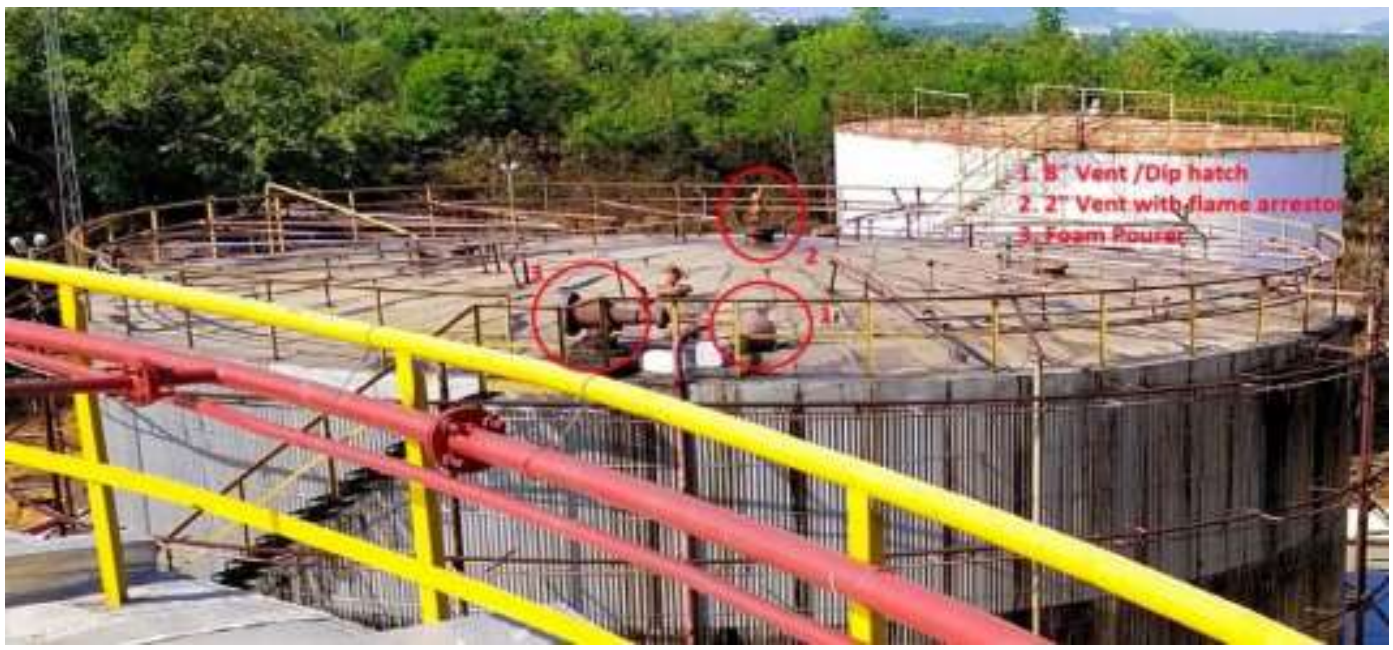

Fig 1: M6 Tank with vents on top of the tank

\subsubsection{Poor Maintenance of M6 Tank}

The last time the tank was cleaned, as per the records, was in 2015. The company informed that their standard protocol is to clean tanks once in 5 years. The literature on Styrene monomer bulk storage in tank suggests the periodical internal cleaning, visual inspection and application of appropriate coating in order to prevent the accumulation of polymer inside of the roof of the tank is undertaken once in every two years. This complacency certainly increased the potential for accumulation of polymerised Styrene monomer vapour at the roof top.

During the observations of technical Committee the inner side of the tank is not lined, rust might have formed at the inside wall due to the long period of absence of inside maintenance of the M6 Tank. The presence of contaminants inside the tank like iron oxide (rust), oxidizing agents, metallic hydrides, iron chlorides and other solid compounds due to insufficient and incorrect cleaning of storage, is a potential source for initiation of polymerization of Styrene which can overwhelm the inhibition effects of TBC. The presence of rust (particles) inside the tank can promote and initiate polymerization.

\subsection{Roof of M6 Tank}

In the case of M6 Tank, the conical roof is supported within the tank interior. This is conducive for Styrene vapour to condense and collect upon the internal structure or surface irregularities available. This condensate does not contain polymerization inhibitor and so it tends to polymerize to polystyrene. It collects on the parts of internal structures and forms stalactites. The company has reported that the float valve got stuck in the stalactites, as a result of which, in October - December 2019, they had to discard the piping connected to the float valve and bring in alternate piping. This clearly proves that the design of roof of this M6 Tank is poor as the structure supporting the roof of this tank is inside the tank, which is more prone for stalactite formation, unlike the modern tank (M5 in this factory) where this roof supporting structure is on the top of the roof outside the tank.

\subsection{Nozzles of M6 Tank}

The number of idle nozzles should also be kept at minimum so as to avoid dead pockets filled with Styrene. There are a total of 17 nozzles of which many are spare nozzles.

\subsection{Life of M6 Tank}

This Styrene storage tank was not subjected to any mechanical integrity assessment study and the plant has never implemented any Life Extension Programme (LEP), since the Styrene tank has performed beyond its designed life period. Even the PESO license was accorded in 1977 (Life span till now 43 years) and if we consider that the tank was earlier used as a molasses tank from the date of factories license in 1967, the life of the tank is 53 years. It is a very risky proposition to store a hazardous chemical in about a 50-year-old tank, that too without implementing any life extension program.

\subsection{Material of the tank}

It is also observed that the Styrene tanks and pipelines of the LG Polymers plant are made of mild steel, which is a serious non-conformance to the laid 


\section{EPRA International Journal of Research and Development (IJRD)}

down standards and guidelines. Lined carbon steel tanks are generally used for the bulk storage of Styrene monomer. The inlet and outlet lines for these tanks are located near the bottom. It is also seen that the bottom and lower 6 to 8 inches $(15-20 \mathrm{~cm})$ of vertical storage tanks have not been coated with inorganic zinc silicate linings to provide electrical grounding. Piping is normally of carbon steel, although stainless steel and aluminum may also be used. Therefore, the M6 Tank is inferior in design in all respects for storing Styrene.

\subsection{Vents open to atmosphere}

As the vents of the tank are open to atmosphere, emissions of Styrene are prevalent. Unlike the modern designs, the tank neither has a flare system that burns the Styrene vapours forming carbon dioxide nor did a cryogenic system to condense Styrene vapours that can be collect separately. The M6 Tank is not provided with any of the above safety systems.

4.7 Change of Design in the suction and discharge lines of recirculation circuit in M6 Tank

The LG Polymers management in its hearing on 7th June 2020, informed the High-Power Committee on a query that they modified the M6 Tank in December 2019 to the present design. On specific query about the changes carried out, they have further informed that the modification had not been informed to PESO or any other concerned statutory organization to get it approved. The company management further informed that they have not informed the modification as they considered it only a change in the piping only. This was a critically wrong assessment on the part of the company. The Committee noted that any modification of equipment or plant should be subjected to HAZOP and Risk Assessment Study. Originally, the tank was having a swing pipe arrangement to discharge the cooled Styrene from the recirculation and refrigeration unit, just below the liquid surface. Thus, the cooled liquid was delivered at the top of the tank and by its chemical property; it would slowly circulate to the bottom of the tank from where it would be pumped through the refrigeration unit. Thus, the contents of the tank were well mixed by the chemical properties, as the denser cold Styrene moves down towards the bottom by gravity and natural convection, such that the temperature would be less thermally stratified in the tank. The management of the company has reported that the float valve got stuck in the stalactites in the M6 Tank, as a result of which, they had to discard the piping connected to the float valve and bring in alternate piping of dip leg arrangement. The alternate piping provided for the cooled Styrene monomer liquid to be delivered at the bottom of the tank. The modified system of the tank, as carried out by December 2019 and confirmed by the company management in its statement.

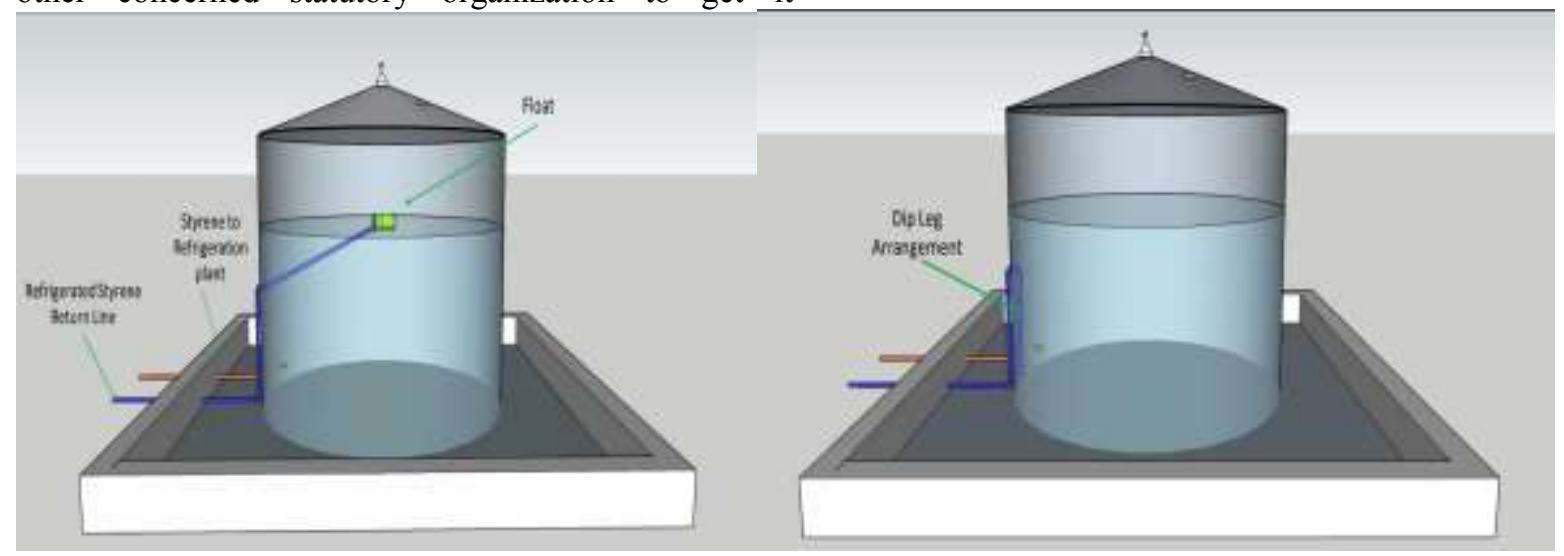

Fig 2: Before and after the modification of Storage tank

The modified piping design provided for the cooled Styrene return line from the refrigeration unit to the nozzle located about $300 \mathrm{~mm}$ above the bottom of the tank. Not only it totally disturbed the chemical circulation system, it led to significant thermal stratification in the M6 Tank with high temperature gradient. The top level of the Styrene monomers in M6 Tank experienced much higher temperatures than the bottom. On the whole this change in design, in a way, sowed the seeds of disaster.

\section{TANK TEMPERATURE MEASUREMENT \& CONTROL}

\subsection{Single Temperature Measuring Probe at} the Bottom

The M6 Tank is provided with a temperature measuring probe (RTD sensor) at the bottom only. The probe is located $0.7 \mathrm{~m}$ from the bottom and about 4.09 $\mathrm{m}$ distance between the discharge port, N13 and the port of the temperature probe, N14.From the location, the Committee is of the view that the location of the 
temperature probe is not adequate to give a representative value of temperature in the tank. The temperature measurement is restricted to the bottom zone liquid, whereas top and middle zones may have different temperatures.

In fact, there must be four or five temperature measurement locations along the $12 \mathrm{~m}$ height of the tank that would have measured the true temperature of the liquid Styrene in the different zones of the tank. For the long-time storage of Styrene, in large tanks, it is necessary to measure the temperatures at different locations across the height of the tank to identity the temperature differentials.

\subsection{Temperature differentials and Mixing in storage tanks}

The density of Styrene is a function of its temperature. When Styrene is warmer; it gets less dense for each increment in degree celsius. This allows for thermal layering; where warmer Styrene moves on to the top of colder Styrene which is defined as "thermal stratification". Due to this, there will always be a level of "self-induced" thermal stratification in the Styrene storage.

It has been estimated that the M6 Tank temperature at $41.7^{\circ} \mathrm{C}$, calculated on the basis of the DCS level percentage data $(56.8 \%)$, recorded on $28-4-$ 2020 , which continued till the early hours of 7 th May 2020.

\subsection{Temperature Profile of Liquid Styrene in M6 Tank}

The management of the company informed that the Standard Operating Procedure provides for their temperature to be kept below $35^{\circ} \mathrm{C}$. This cut off temperature of $35^{\circ} \mathrm{C}$ is not supported by any literature. In fact, the flash point of Styrene Monomer itself is $31^{\circ} \mathrm{C}$. Harold Fisher 17 has simulated autopolymerization initiation at $33.9^{\circ} \mathrm{C}$ after depletion of TBC. In light of the above, the company's protocol temperature of $35^{\circ} \mathrm{C}$ maximum for all their Styrene Storage is highly questionable when the Guidelines given by Chevron Philips 18 and Plastic Europe19 say that the temperature in the Styrene Storage Tank should not exceed $25^{\circ} \mathrm{C}$.

\subsection{Wrongful assumption of Bottom Temperature as Temperature of the Whole Liquid Styrene in M6 Tank}

As the bottom temperature was showing constantly at about $17^{\circ} \mathrm{C}$, the operators in the shifts recorded the same in the logs following the company's SOP. The operator log data in respect of M6 Tank temperature is conforming to the DCS log in the control room. There is no separate temperature data collection within the M6 Tank by the operator, except the inlet / outlet pipe data temperature recording during operations. The ignorance and negligence towards this fact of temperature at the top level being much higher than $17^{\circ} \mathrm{C}$ has been one of the major factors in making the management complacent and taking no corrective action.

As the ambient temperatures are high in summer, the Styrene vapour in the vapour space of tank is heated due to heat leaks from the roof of the tank. The vapour in the tank is liable to be heated through several flanges and other parts which were not insulated. Invariably, the liquid surface gets heated up and reaches an equilibrium temperature with the heated vapour. However, there is no temperature probe for measuring the vapour temperature in the top of the tank. The tank had only one temperature measurement probe at the bottom of the tank.

\section{RECIRCULATION AND REFRIGERATION SYSTEM}

Under no circumstances the temperature of Styrene in whole tank should exceed $25^{\circ} \mathrm{C}$ according to the standard guidelines for Styrene storage. Hence, it necessitates maintenance oflower storage temperature in the tank. Higher temperatures are bound to cause Styrene vaporization and subsequent build-up of polymer. Usually, the preferred storage temperature is in the range of $10-18^{\circ} \mathrm{C}$. If the temperature approaches $20^{\circ} \mathrm{C}$, the tank contents must be cooled. Thus, proper refrigeration-recirculation systems need to be provided. As the tank is insulated, the exothermic polymerization heat cannot be dissipated. The M6 Tank does not have proper mixing arrangement to take care of any increase in temperature in middle and upper zones. Although the company has stated that there are temperature alarms at $35^{\circ} \mathrm{C}$ and $37.5^{\circ} \mathrm{C}$, the temperature data recorded in the DCS on the 7 th of May does not record any temperature alarm either at $35^{\circ} \mathrm{C}$ or $37.5^{\circ} \mathrm{C}$. The Technical Committee, in its report has mentioned that there is no temperature alarm also for the M6 Tank. The temperature of liquid Styrene Monomer is a very crucial factor. The temperature maintenance throughout the large storage tanks at 15$20^{\circ} \mathrm{C}$ is essential in light of possibility of runaway polymerization characteristic of Styrene. 


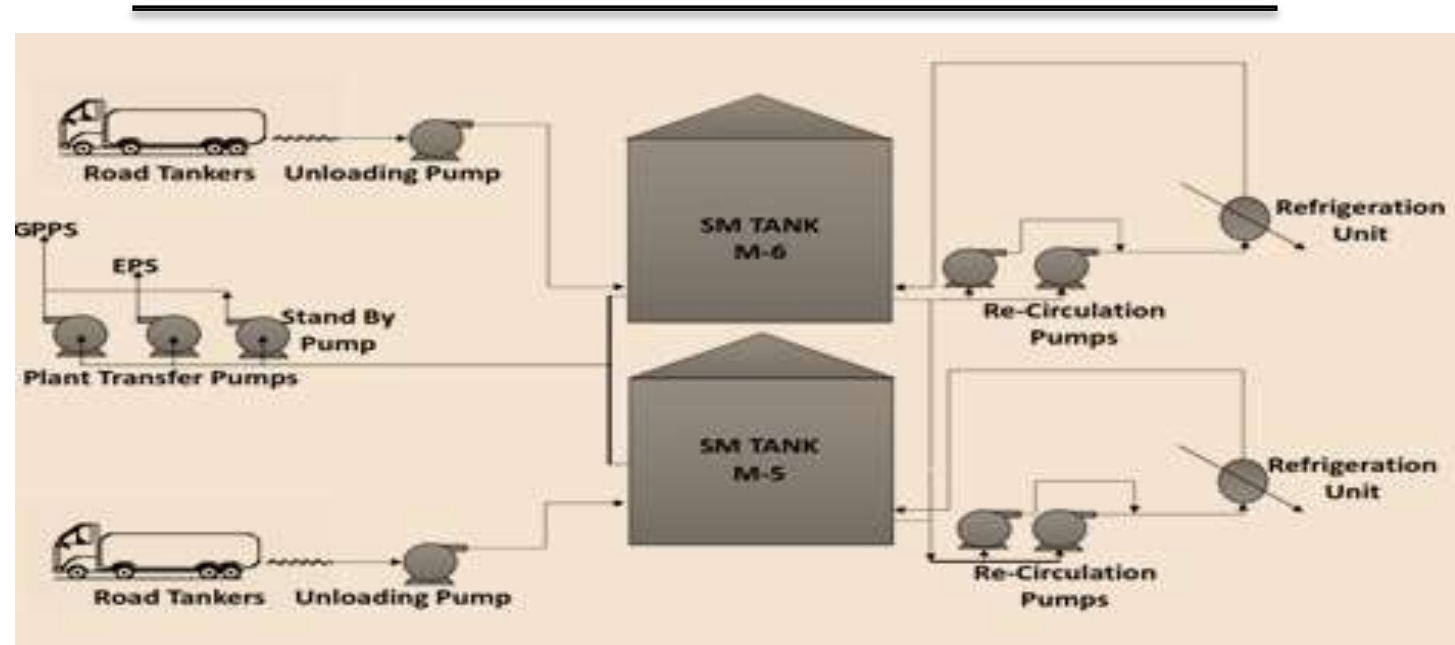

Fig 3 : PFD of Styrene Monomer Handling Plant

\subsection{Inadequate Time for Refrigeration and Manual Operation}

The refrigeration system of the M6 Tank (as well as of the M5 tank) are manually operated. The company management informed that it is their normal practice to switch on the refrigeration / cooling system at 08:00 a.m. and close at 05:00 p.m. every day, except when unloading of Styrene Monomer from tanker takes place, during which refrigeration system is kept on. The management also informed that all through the lockdown period, the refrigeration subsystem was operated from 08:00 a.m. to 05:00 p.m. However, on the 6th May 2020, as per the logbook, the Director of Factories has reported that the refrigeration system was switched off at 3:45 p.m. For a place like Visakhapatnam, with temperatures mostly ranging from $20^{\circ} \mathrm{C}$ to $36^{\circ} \mathrm{C}$, it is but essential to operate the refrigeration system on a continuous basis to ensure temperature at all levels of tank below $20^{\circ} \mathrm{C}$. This is one of the major shortcomings in the refrigeration system followed by the LG Polymers.

The refrigeration system of the Styrene storage tank should have been provided with a fully automated instrumentation system of adequate safety integrity level, coupled with the temperature sensor for automatic switching-on and off the system based on the temperature reading of the gauges. The non-provision of this system has permitted the human error and onset of reactive hazard resulting in the release of toxic vapour cloud.

\subsection{Improper Cooling of Styrene Monomer due to Design Change in the Refrigeration}

The float swing pipe arrangement was replaced with dip leg arrangement with release of cooled Styrene Monomer liquid at virtually at the bottom of the tank viz., $300 \mathrm{~mm}$ from the bottom. Similarly, the liquid
Styrene monomer is taken into the refrigeration cooling system from the N13 port, located at nearly the bottom of the tank at $100 \mathrm{~mm}$. It totally destroyed the natural chemical circulation (mixing) system. Moreover, it resulted in cooled liquid Styrene Monomer being pumped for further cooling in the refrigeration system. This is the cause why the temperatures at the bottom of the M6 Tank recorded low temperatures in the range of $17^{\circ} \mathrm{C}$.

\subsection{Other possibilities}

- Possibility of R-22 contamination of Styrene Monomer in M6 Tank

- Insufficient Capacity of refrigeration unit

- Clogging of Valves and Lines of the Refrigeration Systems

\section{POLYMERIZATION \& RUNAWAY REACTION}

A critical question to be answered is why polymerization took place, why temperature rose and why runaway reaction took place. LG Polymers in its reports has stated that "Polymerization generally takes place by free radical reactions initiated thermally or catalytically. Polymer formation occurs slowly even at ambient temperatures and becomes rapid at elevated temperatures". The Committee has reflected on a lot on the issue and has concluded that there are mainly two possibilities or a combination of both the possibilities for initial polymerization viz. (a) Thermal Radical Polymerization or (b) Polymerization due to presence of a catalyst or a combination of both (a) and (b) which are listed below.

\subsection{Thermal radical polymerization}

As the temperature in the upper zone of the M6 Tank was higher than $35^{\circ} \mathrm{C}$, (estimated to be $41.7^{\circ} \mathrm{C}$ ) the effectiveness of the TBC inhibitor had been lost and 


\section{SJIF Impact Factor: 7.001| ISI I.F.Value:1.241| Journal DOI: 10.36713/epra2016 ISSN: 2455-7838(Online) EPRA International Journal of Research and Development (IJRD) Volume: 5 | Issue: 8 | August 2020 \\ - Peer Reviewed Journal}

thermal radical polymerization must have set in and being an adiabatic tank (insulated) the heat generated could not be dissipated. It must have resulted in further temperature increase leading to further polymerization and finally leading to runaway reaction. It is at temperatures above $65^{\circ} \mathrm{C}$, when a runaway polymerization reaction occurs.

When a runaway polymerization occurs, temperatures can quickly reach the boiling point of Styrene monomer. Vapors may erupt violently from tank vents or if vents become plugged with polymer, excessive pressure can be generated that may rupture the containment vessel.

\subsection{Presence of Catalyst}

The polymerization of Styrene vapour in the storage tank cannot be prevented with inhibitor as the same is ineffective for vapours, making accumulation on the inside of the roof top and formation of stalactite inevitable. These stalactites eventually cause contamination and potentially create bulk polymerization hotspot where the exothermic polymerization reaction can propagate.

It is possible, when the accumulated polymer falls into the Styrene below, it can act as a catalyst, provide the initial polymer seed and further trigger the polymerization. As the Styrene level in M6 Tank at the time of accident was about $7 \mathrm{mts}$., the polymer lumps if fallen, must have fallen through a depth of about $5 \mathrm{mts}$ causing an impact / friction between lumps and Styrene liquid. This may have generated more free radicals of Styrene, initiating or aggravating the polymerization at the top layers of Styrene in the tank and planted the seed for creation of hot spots at the top layers of Styrene in the tank towards runaway polymerization which the management had failed in capturing it due to lack of temperature measurement system at the top level of the tank. The M6 Tank is an old tank with high possibilities of rust and other contamination. These contaminations could have also acted as catalyst and led to further polymerization and finally runaway reactions.

\subsection{Increase in temperature, runaway} reaction \& vaporization

Combination of both the possibilities of Thermal Radical Polymerization and Polymerization due to presence of catalyst, caused the polymerization in the M6 Tank. Styrene monomer polymerization reaction is exothermic evolving $(16700 \mathrm{kcal} / \mathrm{kg}$ mole or 160.36 $\mathrm{kcal} / \mathrm{kg}$ ). The M6 Tank is insulated and thus, there is no provision for heat dissipation. Thus, the initial polymerization led to further increase in temperature, which led to further increase in polymerization. Without any effective inhibitor being available in the
M6 Tank, the temperatures in the hotspot areas in the top layers of the tank increased to above $65^{\circ} \mathrm{C}$. At temperatures above $65^{\circ} \mathrm{C}$ runaway polymerization reaction occurs. If excess heat is not adequately dissipated, the product temperature will rise with a subsequent rise in the rate of polymerization.

\section{LOCKDOWN PERIOD}

The analysis of the lockdown period is very important as the company management in their statement have stated that the accident occurred due to the long storage arising during the lockdown period, without the regular operations. In the list of 25 essential industries "Manufacturing Polystyrene and Expandable Polystyrene and Engineering Plastics Compounds", are not included. Subsequently, the company applied for minimum staff for maintaining the factory. Permission was granted on 28th March 2020 and passes were issued for 45 personnel @ 15 per shift.

Further, the management did not take up the matter with the higher authorities like the Commissioner of Industries, the Principal Secretary of Industries Department, Government of Andhra Pradesh, if they had felt the absolute necessity for continuing the operations during the Covid-19 lockdown period, keeping the safety of the factory into account, in view of hazardous Styrene in bulk storage. The Technical Committee has reported that it is learnt that all the Styrene-based plants around the world are being operated smoothly in spite of the Covid-19 lockdowns in several countries and however the management of the company did not take up this issue in full earnestness.

As per the SOPs for handling and storage of Styrene given by the company, the operators have been maintaining parameters and noting the values in the logs. From the analysis of Styrene samples collected from the storage M6 Tank along with other tanks, it can be seen that the measurements were carried out in the same manner as before the lockdown. While, the minimum sampling was conducted, no special measures were taken for the lockdown period. In summer, it warrants daily sampling and testing should be carried out as per the guidelines But, in LG Polymers, daily sampling and testing was not practiced even in normal times and as stated above no special measures were taken during the lockdown period.

\section{White Cloud Formation of Styrene vapor}

As light passes through a cloud of vapour, it passes through the liquid droplets in the vapor making its appearance white. This concept is known as Mie scattering. The moisture in the original liquid Styrene is also vaporised when the temperature in the tank reaches 


\section{EPRA International Journal of Research and Development (IJRD) \\ Volume: 5 | Issue: 8 | August 2020 \\ - Peer Reviewed Journal}

$100^{\circ} \mathrm{C}$. The white vapor is an admixture of Styrene vapour, water vapour and the water present in the air as humidity.

\section{KNOWLEDGE / TALENT DEFICIT}

There was a dearth of knowledge talent among the top, middle and shift management in LG Polymers. Many chemical engineers with $20-30$ years of experience in the Styrene and its polymers plants have either retired or left the company for better opportunities. Most of the present shift in-charges / engineers are not qualified engineers. The operators once upon a time with science degree / intermediate qualifications have been promoted based on their experience as engineers. These candidates may run the process plants meticulously according to the process operating manuals and SOPs. But their knowledge and skills would not be adequate when faced with a challenge or an emergency. Such decision-making experience and capability are important in dealing with major upsets during processing hazardous chemicals like Styrene.

\section{ROOT CAUSE}

The total release of Styrene vapour up to 07:40 a.m. on 8th May 2020 is approximately 562.43 MT. The total loss of Styrene till 11:52 a.m. is approximately $818.16 \mathrm{MT}$. This is based on the assumption that $95 \mathrm{MT}$ of Styrene monomer was withdrawn during the emergency response measures; otherwise the quantities will be 95 MT more. The fishbone diagram explaining the root causes is also prepared.

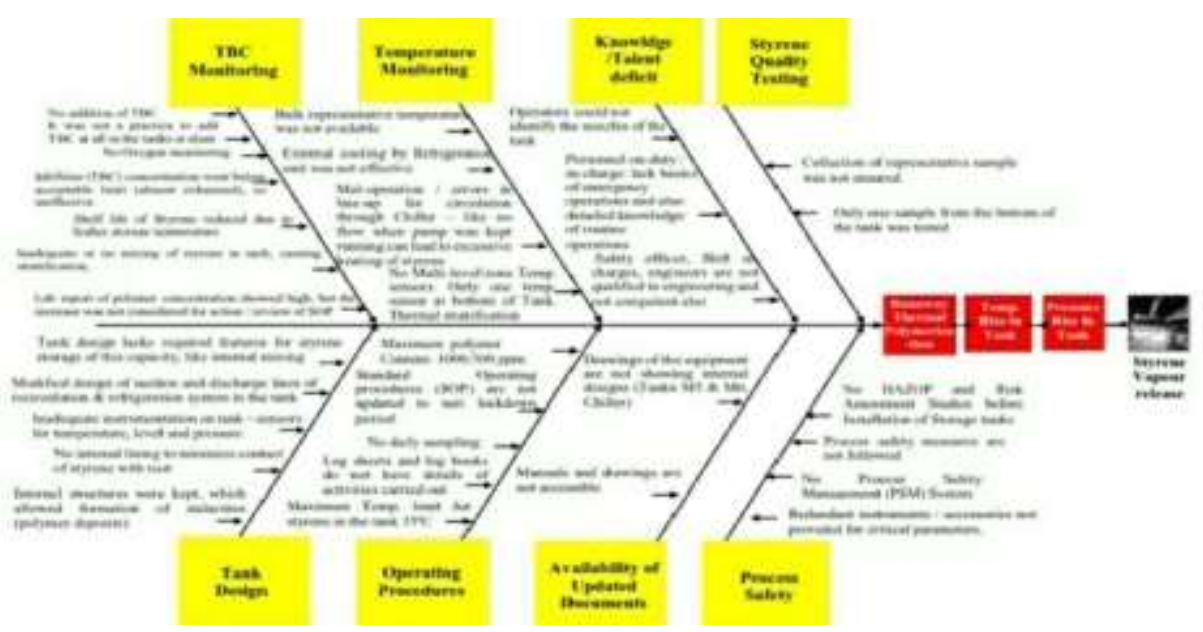

Fig 4: Ishikawa fish bone diagram explaining the root causes 


\section{EPRA International Journal of Research and Development (IJRD)}

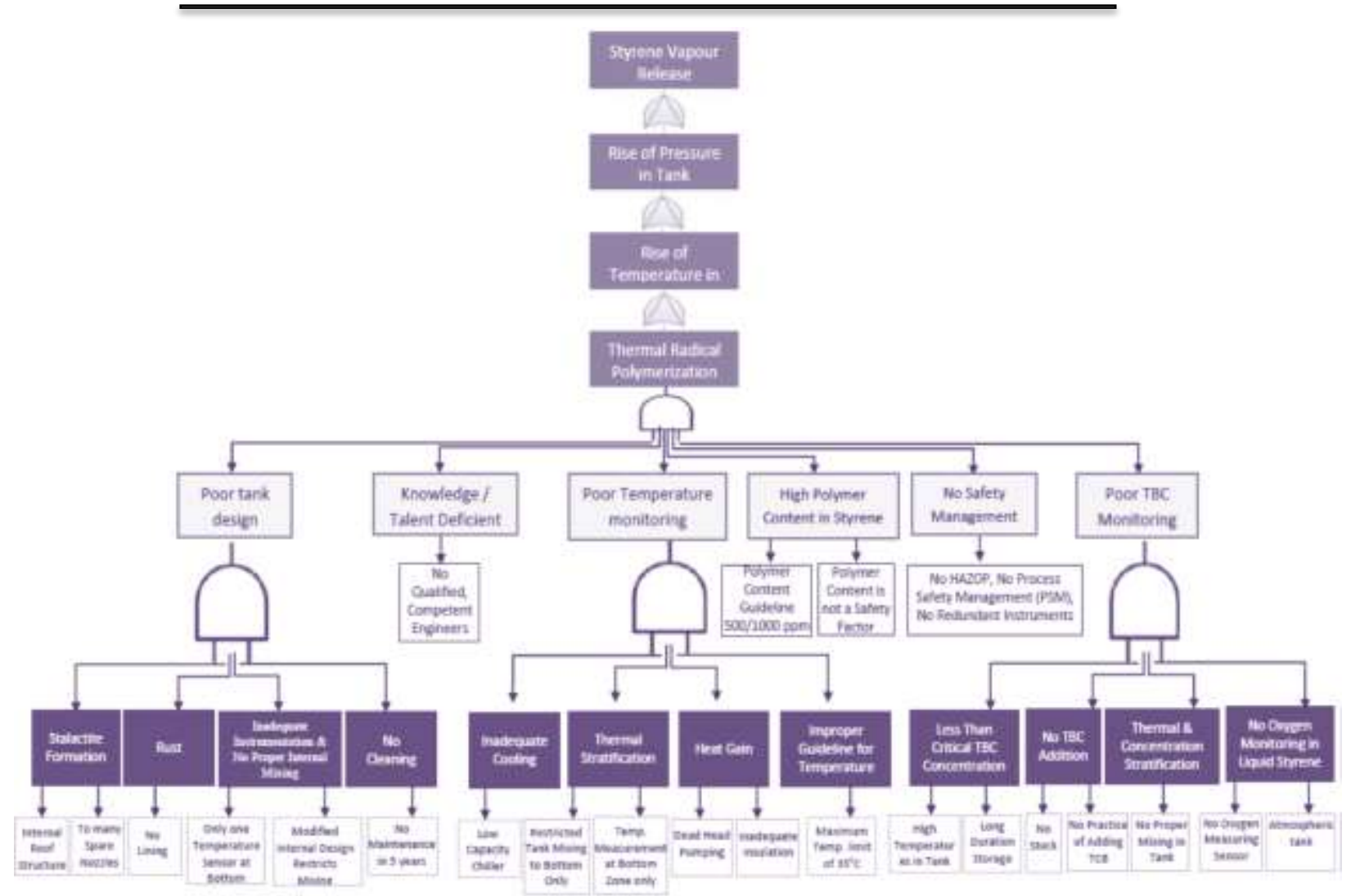

Fig 5: Fault Tree Diagram (FTD) explaining Styrene Vapor release

\subsection{Safety Protocols}

- The Occupier of the factory has failed to provide and ensure the information, instruction, training and supervision to ensure health and safety of all workers during start-up operations. The restarting process has not been carried out as per the standard procedures, protocols and guidelines in the presence of entire technical team, including safety officer and factory medical officer of the factory.

- The Occupier has failed to provide and maintain the plant and systems to be safe and without risks to the health of the workers. The arrangements for ensuring safety and health of the workers by ensuring absence of risks in connection with the use, handling, storage and transport of chemicals in the factory premises have also been not provided.

- The Pre-Startup Safety Review (PSSR), which is a safety review conducted prior to startup of a processing/manufacturing plant to ensure that installations meet the original design or operating intent, to catch, re-assess any potential hazard due to changes during the lockdown period, has not been done. The identified hazards through the Pre-Startup Safety Review (PSSR) study have not been eliminated, prevented and controlled before starting the operations in plant. A record on this was also not maintained for the review by the regulatory authorities.

- The two Styrene storage tanks have not been provided with a buffer tank inter- connected to these tanks and in case of emergency in a tank, the Styrene in the damaged or affected tank might have been transferred to the buffer tank thus preventing, controlling and reducing the emergency.

- The Styrene storage tanks have not been marked, labeled and/or placarded with Hazardous Material Information System (HMIS).

- The plant has not implemented any training programme covering entire management representatives, staff and workers, at least once in every year, consisting of the following training modules:

$>$ Properties and health hazards of Styrene.

$>$ Styrene physical hazards including the potential for fire and explosion.

$>$ Styrene's primary routes for entry into body.

$>$ Safe work and good housekeeping practices. 


\section{EPRA International Journal of Research and Development (IJRD)}

$>$ The importance of protection from Styrene contact; the proper clothing and cleaning requirements.

$>$ Signs and symptoms of Styrene exposure and action to be taken and medical conditions aggravated by exposure to Styrene.

$>$ The care that must be taken whenever and wherever Styrene is used, handled, stored and transported.

$>$ The availability of written Styrene usage, health hazard and training program procedures.

$>$ Emergency procedures for leaks, spills, and fires, including protective clothing to be worn in such instances.

\section{CONCLUSION}

The Occupier and Manager of the factory have individually failed to provide, maintain and monitor safe and risk free work environment by ensuring that the permissible limits of exposure of Styrene monomer (TWA : $50 \mathrm{ppm}$ and $215 \mathrm{mg} / \mathrm{m} 3$; STEL: $100 \mathrm{ppm}$ and $425 \mathrm{mg} / \mathrm{m} 3$ ) as laid down under Section $41-\mathrm{F}$ of the Factories Act, 1948, are never exceeded.

In the light of the causes mentioned above, the accident in the Styrene storage M6 Tank can be attributed to poor design of tank, inadequate refrigeration and cooling system, absence of circulation \& mixing systems, inadequate measurement parameters, poor safety protocol, poor safety awareness, inadequate risk assessment and response, poor process safety management systems, slackness of management, insufficient knowledge amongst staff, insufficient knowledge of the chemical properties of Styrene, especially during storage under idle conditions. LG Polymers does not have any process safety management system. On the whole, it can be concluded that LG Polymers did not have proper safety protocols and violated a number of safety protocols.

Mistakes could be catastrophic in a chemical plant, but it is a great opportunity to learn from previous incidents and develop new procedures, practices and management systems and design a safer plant .These incidents reveal many hidden facts about safety and provide efficient tools for prevention of similar incidents in the future.

\section{REFERENCES}

1. https://www.ap.gov.in/wpcontent/uploads/2020/07/The-High-PowerCommitee-Report.pdf

2. "Visakhapatnam gas leak live updates". The Hindu. 7 May 2020. Retrieved 7 May 2020.
3. ^ Bhashkar, Utpal (9 May 2020). "LG Polymers admits leaking vapor from gas storage tank caused Vizag tragedy". The Livemint. Retrieved 10 May 2020.

4. ^ Jump up to: $:^{\boldsymbol{b}}$ "Vizag Gas Leak LIVE Updates: 11 Dead, Over 5,000 Sick After Leak at LG Polymers Plant; CM Announces Rs 1 Crore for Kin of Deceased". News18. 7 May 2020. Retrieved 7 May 2020.

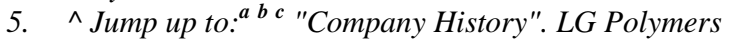
India.

6. ^ Oct 10, TNN | Updated:; 2012; Ist, 01:54. "'Mallya's UB group involved in land scam'| Hyderabad News - Times of India". The Times of India. Retrieved 3 July2020.

7. ^Jump up to: ${ }^{\boldsymbol{a} \boldsymbol{b} \boldsymbol{c} \boldsymbol{d} \boldsymbol{e}}$ "Indian LG Plant Lacked Environmental Clearance Before Leak". The Associated Press (AP). U.S. News \& World Report. 13 May 2020. Retrieved 14 May2020.

8. ^ Jump up to: ${ }^{\boldsymbol{a} \boldsymbol{b} \boldsymbol{c}}$ "Thick air, pungent smell: How gas leakage tragedy unfolded at Visakhapatnam's LG Polymers plant". The Indian Express. 7 May 2020. Retrieved 7 May 2020.

9. ^ Jump up to: ${ }^{\boldsymbol{a}} \boldsymbol{b}$ "(Published in the Gazette of India, Extraordinary, Part-II, and Section 3, Sub-section (ii) Ministry of Environment and Forests, New Delhi, 14th September, 2006Notification" (PDF). Ministry of Environment, Forests and Climate Change (MoEFCC). 14 September 2006. Retrieved 14 May 2020.

10. ^ Jump up to: ${ }^{\boldsymbol{a} \boldsymbol{b}}{ }^{c}$ Aryan, Ashish; Mukul, Pranav (8 May 2020). "Vizag gas leak: Don't have green nod, company told state last May". The Indian Express. Retrieved 15 May2020.

11. ^ "Vizag gas leak: LG Chem plant operated with state permits since 1997 despite lacking environmental clearance from Centre". The Associated Press (AP). The Firstpost. 13 May 2020. Retrieved 14 May 2020.

12. ^ "Vizag gas tragedy: LG Polymers lacked environmental clearance before styrene gas leak". The India TV news. 13 May 2020. Retrieved 15 May 2020.

13. ^ Jump up to: ${ }^{\boldsymbol{a}}$ "Hundreds injured and eight dead in Indian gas leak". BBC News. 7 May 2020. Retrieved 7 May 2020.

14. ^ Jump up to: ${ }^{a b c}$ "Vizag Gas Leak LIVE Updates: 8 Dead, 300 Hospitalised \& Over 5,000 Sick After Leak at LG Polymers Chemical Plant; PM Modi Calls for NDMA Meet at 11am". News18. 7 May 2020. Retrieved 7 May 2020.

15. ^ Gettleman, Jeffrey; Raj, Suhasini; Schultz, Kai; Yasir, Sameer (7 May 2020). "Gas Leak in India at LG Factory Kills 11 and Sickens Hundreds". The New York Times. ISSN 0362-4331. Retrieved 7 May 2020. 


\section{SJIF Impact Factor: 7.001| ISI I.F.Value:1.241| Journal DOI: 10.36713/epra2016 ISSN: 2455-7838(Online) EPRA International Journal of Research and Development (IJRD)

16. ^ "Safe handling and storage of styrene monomer" (PDF). Chevron Phillips Chemical. Retrieved 8 May 2020.

17. ^ "Gas Leak in Vizag: Glitch in refrigeration unit led to Vizag gas leak|Visakhapatnam News Times of India". The Times of India. 7 May 2020. Retrieved 7 May 2020.

18. ^Jump up to: ${ }^{\boldsymbol{a}}$ "Visakhapatnam gas leak live updates: Jagan announces Rs. 1 crore relief". The Hindu. 7 May 2020. ISSN 0971-751X. Retrieved 7 May 2020.

19. ^Jump up to: ${ }^{a b}$ "Massive gas leak in Visakhapatnam, thousands affected, Centre monitoring situation: 10 points". India Today. Retrieved 7 May 2020.

20. ^ Jump up to: ${ }^{a b} G$, Siva. "Vizag LG Polymers Gas leak: 11 dead, over 5,000 fall sick after gas leak from LG Polymers". The Times of India. Retrieved 7 May 2020.

21. ^ Ellis-Petersen, Hannah; Safi, Michael; Dhillon, Amrit; Chandrasekhar, Aruna (7 May 2020). "Gas leak at chemical factory in India kills at least nine and hospitalises hundreds". The Guardian. ISSN 0261-3077. Retrieved 7 May 2020.

22. ^Jump up to: ${ }^{\boldsymbol{a}}{ }^{\boldsymbol{b}}$ Bhattacharjee, Sumit (7 May 2020). "Visakhapatnam gas leak claims 11 lives; over 350 in hospitals". The Hindu. Retrieved 7 May 2020.

23. ^ Sud, Vedika; Sharma, Akanksha; Yeung, Jessie; Mitra, Esha; Reynolds, Emma. "Toxic gas leak at Indian chemical plant kills at least 11 and hospitalizes hundreds". CNN. Retrieved 7 May 2020.

24. ^ "Gas Leak Kills 13, Injures Hundreds in Visakhapatnam, Andhra Pradesh". The Weather Channel. Retrieved 8 May 2020.

25. ^ "Vizag Gas Leak News Update: No! There was no second Gas Leak in Vizag". SA News Channel. 8 May 2020.

26. ^ "'Evacuation precautionary': Vizag police dismiss report of second gas leak". Hindustan Times. 8 May 2020.

27. ^Jump up to: ${ }^{a b c}$ "Experts detect more gas leak risks at LG Polymer factory in Vizag". The Deccan Chronicle. 12 May 2020. Retrieved 15 May 2020.

28. ^ Jump up to: ${ }^{\boldsymbol{a} \boldsymbol{b} \boldsymbol{c}}$ "Vizag gas leak Updates: Andhra govt to airlift $500 \mathrm{kgs}$ of PTBC from Daman to neutralise chemical; special NDRF team to fly in from Pune". Firstpost. Retrieved 7 May 2020.

29. ^ Vora, Rutam. "Gujarat to airlift PTBC chemical for Vizag gas leak crisis". Business Line. The Hindu. Retrieved 7 May 2020.

30. ^ "LG Polymers in Vizag gets 'Styrene inhibitor' to boost safety after gas leak". The Hindustan Times. 14 May 2020. Retrieved 14 May 2020.

31. ^ "Visakhapatnam gas leak:LG Chem dispatches technical team from Seoul for investigation, rehabilitation works". The Hindu. 13 May 2020. Retrieved 14 May2020.

32. ^ "Visakhapatnam Gas Leak Updates: Day after tragedy, gas fumes begin leaking again". India Today. Retrieved 7 May 2020.

33. ^ Pathak, Analiza (7 May 2020). "Technical glitch in refrigeration unit caused Visakhapatnam gas leak: Official". India TV News. Retrieved 8 May 2020.

34. ^ "Vizag gas leak: What is styrene and how does it affect the body?". The News Minute. 7 May 2020. Retrieved 7 May 2020.

35. ^ "Vizag gas leak live news updates: Toll rises to 11; NHRC sends notice to Andhra Pradesh govt, Centre". The Times of India. Retrieved 7 May 2020.

36. ^Basu, Mohana (7 May 2020). "How styrene, chemical being blamed for Vizag gas leak deaths, affect human body". ThePrint. Retrieved 7 May 2020.

37. ^ "Plea in NGT seeks judicial probe into Visakhapatnam gas leak incident". Asian News International. 7 May 2020. Retrieved 7 May 2020.

38. ^ "NGT to take up Visakhapatnam gas leak case on Friday". The Statesman (India). 7 May 2020. Retrieved 7 May 2020.

39. ^ "Vizag Gas Leak: NGT Issues Notice To Centre, Directs LG Polymers To Deposit Rs 50 Cr". Press Trust of India. The Outlook. Retrieved 8 May 2020.

40. ^ Ghosh, Shinjini (8 May 2020). "Visakhapatnam gas leak: NGT directs LG Polymers India to deposit ₹50 crore". The Hindu. Retrieved 8 May 2020.

41. ^ "Probe blames safety lapses for deadly India gas leak". AP NEWS. 31 May 2020. Retrieved 1 June 2020.

42. ^ "NHRC notice to Andhra Pradesh Government and Centre over deaths and sufferings to several people due to styrene gas leakage in Vizag District (07.05.2020)". National Human Rights Commission of India. Retrieved 7 May2020. 